\title{
Clinical Spectrum of Intracranial Bleeds in Patients with Bleeding Disorders- Experience from a Tertiary Center in Karnataka
}

\author{
Meera V. ${ }^{1}$, Smitha R. ${ }^{2}$ \\ ${ }^{1}$ Department of Clinical Haematology, Bangalore Medical College and Research Institute, Bangalore, Karnataka, India. \\ ${ }^{2}$ Department of Clinical Haematology, Bangalore Medical College and Research Institute, Bangalore, Karnataka, India.
}

\section{ABSTRACT}

\section{BACKGROUND}

The most frequent emergency event in haemophilia and other bleeding disorders is intracranial haemorrhage (ICH), most of which is caused by trivial trauma, affecting around $3-10 \%$. We studied the spectrum of presentation of ICH at our institute.

\section{METHODS}

This was retrospective analysis of all patients with diagnosed or suspected bleeding diathesis and ICH presenting at the Clinical Haematology Department, BMCRI. They underwent complete coagulation workup, inhibitor screening, plain CT- brain and other relevant investigations.

\section{RESULTS}

$3.26 \%$ of patients with bleeding disorders presented with ICH of over 2 years. M:F ratio was $13: 1.78 .6 \%$ had Haemophilia A, 7.1\% each had Haemophilia B, Factor XIII deficiency and Hypofibrinogenemia. 13 (92.9\%) had severe Haemophilia A or B and $1(7.1 \%)$ had mild Haemophilia B. Their ages ranged from 2 - 69 years. 50\% were adults with the oldest being 69 years. Out of 7 children with Intracranial bleeds, 5 (71.4\%) were $<5$ years. 2 (18.2\%) with Haemophilia A had inhibitors. None were hypertensive. There was recent history of trauma in 9 (64.3\%). All (100\%) had severe headache, $21.4 \%$ had vomiting and $28.6 \%$ had seizures at presentation. Subdural haemorrhage was seen in 9 (64.3\%), subarachnoid haemorrhage in $1(7.1 \%)$, epidural bleed in 1 (7.1\%), and intraparenchymal bleed in $3(21.4 \%)$. All patients received appropriate factor replacement and supportive treatment. 9 (64.3\%) received factor replacement only, 5 (35.7\%) with SDH required additional burr hole evacuation. $2(14.3 \%)$ patients died and $12(85.7 \%)$ responded to treatment. None had sequelae in this series.

\section{CONCLUSIONS}

$3.26 \%$ of our cohort presented with intracranial bleed over a period of two years. Majority with ICH were Haemophilia A and had severe deficiency with history of trauma. Headache is the commonest presentation and astute and keen clinical suspicion is paramount for instituting early treatment. SDH was most common in our series and majority responded to conservative management with factors.
Corresponding Author:

Dr. Meera $V$,

Department of Clinical Haematology,

Bangalore Medical College

\& Research Institute, Fort,

Bangalore-2, Karnataka, India.

E-mail: meerachakra@yahoo.com

DOI: $10.14260 / \mathrm{jemds} / 2020 / 385$

Financial or Other Competing Interests: None.

How to Cite This Article:

Meera V, Smitha R. Clinical spectrum of intracranial bleeds in patients with bleeding disorders- experience from a tertiary center in Karnataka. J. Evolution Med. Dent. Sci. 2020;9(23):1752-1755, DOI: 10.14260/jemds/2020/385

Submission 14-10-2019,

Peer Review 15-05-2020,

Acceptance 21-05-2020,

Published 08-06-2020.

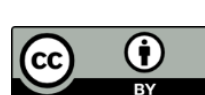

\section{KEY WORDS}

Haemophilia, Intracranial Bleeds, Bleeding Disorders. 


\section{BACKGROUND}

The commonest emergency event in bleeding disorders is intracranial haemorrhage (ICH), triggered by trivial trauma, affecting around $3-10 \%$. There is scant data on the prevalence of ICH and their outcomes in developing countries like India. Favourable outcomes following an ICH depends on immediate recognition and prompt replacement therapy. These are life threatening events and emergency neurosurgical interventions may be needed in case of large bleeds. Small volume bleeds with insignificant mass effect and midline shift are managed conservatively with Antihaemophilic factor support and close neurological monitoring. Most of the bleeding events inside the skull or spinal canal are caused by trauma. However, since patients with bleeding disorders can experience bleeding even weeks after a minor head injury, a history of head trauma may be hard to determine, particularly in children. Spontaneous CNS bleeding is rare except when there has been a recent antecedent CNS haemorrhage (i.e., a recurrent bleed at a previously injured site) or when there is an associated anatomic lesion like aneurysm or arterio-venous malformation which predisposes to bleeding. Predisposing risk factors for intracranial haemorrhage include HIV infection, presence of inhibitor, and age less than 5 years or over 51 years. The risk of traumatic bleeds affects patients with all degrees of severity. ${ }^{1-5}$

Since the central nervous system is enclosed in a bony structure, there is only limited scope for expansion when bleeding occurs and compression of the brain tissue, nerves, or spinal cord occurs quickly. Clinical symptoms depend on the site of bleeding. Clinical presentation in CNS bleeding are nausea, irritability, or headache indicating increasing intracranial pressure and varies from mild to severe. Soon after a subarachnoid, epidural or intracerebral haemorrhage, patient maybe asymptomatic and symptoms are delayed for days to a week after the trauma. Later symptoms of intracranial bleed are stiff neck or back, confusion, changes in mentation, slurred or confused speech, ataxia, blurred or double vision, nystagmus, unequal pupil size, muscle weakness or paralysis, paraesthesia or numbness, and seizures. When these clinical signs are present, it indicates that there is a significant accumulation of blood within the skull with brain compression and damage. ${ }^{6-8}$

We studied the spectrum of presentation of ICH at our institute with goals to establish the incidence, location of bleeding and disabling sequels and look at risk factors for ICH. We present data from analysis of 430 patients with bleeding disorders who experienced ICH in our Center over the last 2 years.

\section{METHODS}

This was retrospective analysis of all patients with diagnosed or suspected bleeding diathesis and ICH presenting at the Clinical Haematology Department, BMCRI, Bangalore. Patients without confirmed bleeding disorder and/or with liver dysfunction or those on anticoagulation which can affect factor level were excluded. Everyone underwent inhibitor screening prior to starting treatment. ICH was identified by a detailed medical history, general clinical examination and neurological examination including Glasgow Coma Scale (GCS) scoring ${ }^{9}$ and computed tomographic imaging. Everyone were evaluated for trauma and injury. CT scan of the brain was performed after giving the patient a $100 \%$ correction for the deficient factor immediately. Advice of the neurosurgeon sought for all. Conservative factor replacement therapy with $100 \%$ correction for 3-4 days followed by $50-60 \%$ correction for 7 days was given and tapered and stopped by 14 days, along with the antifibrinolytic agent epsilon amino caproic acid. All the patients were put on long-term anticonvulsants-dilantin or levetiracetam after the episode. All the patients were tested for inhibitors and treated accordingly if found positive.

\section{Statistical Analysis}

Statistics were analysed using Microsoft Word and Excel sheet and presented as percentages. Relevant data was analysed and expressed as Mean \pm SD (standard deviation) and compared using one-way ANOVA.
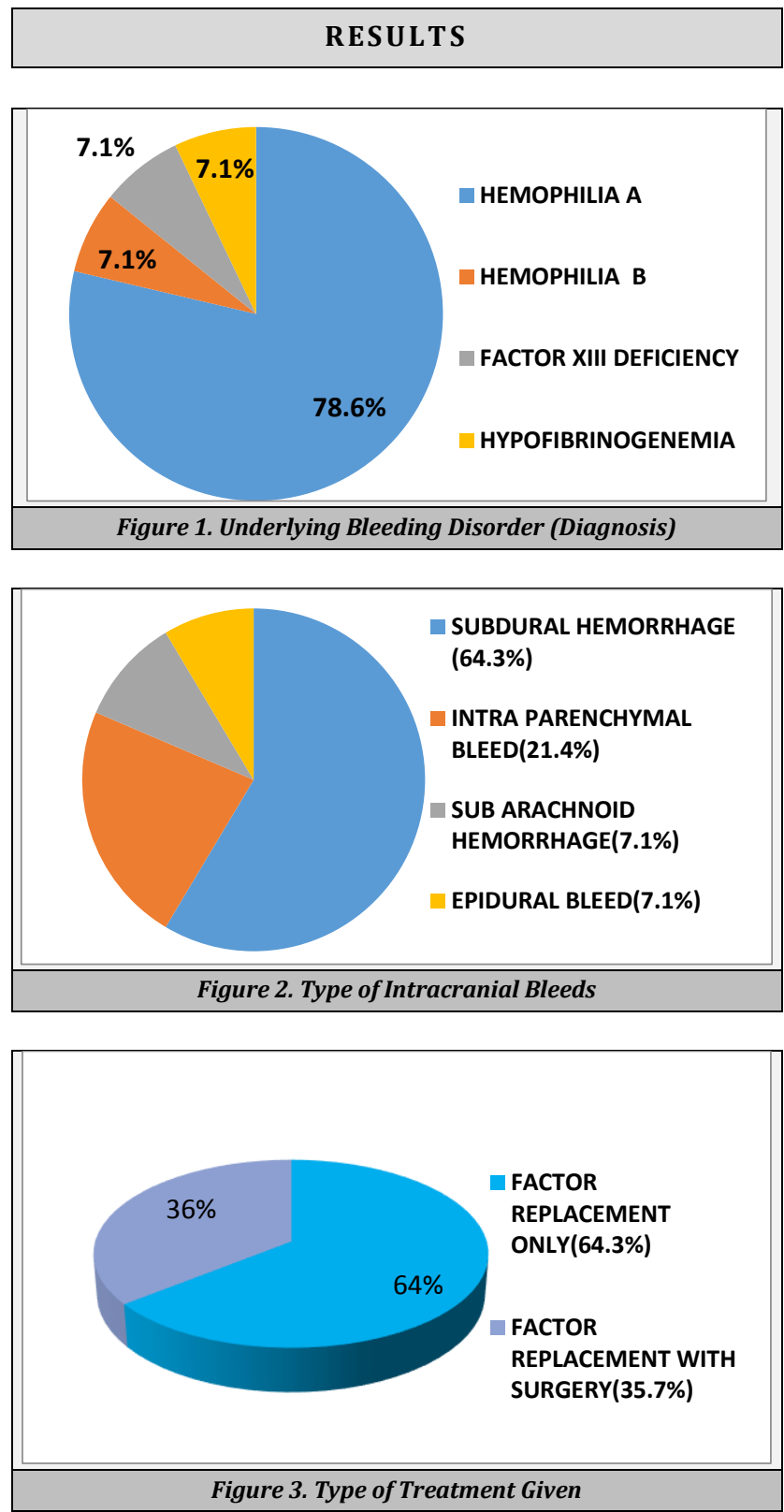


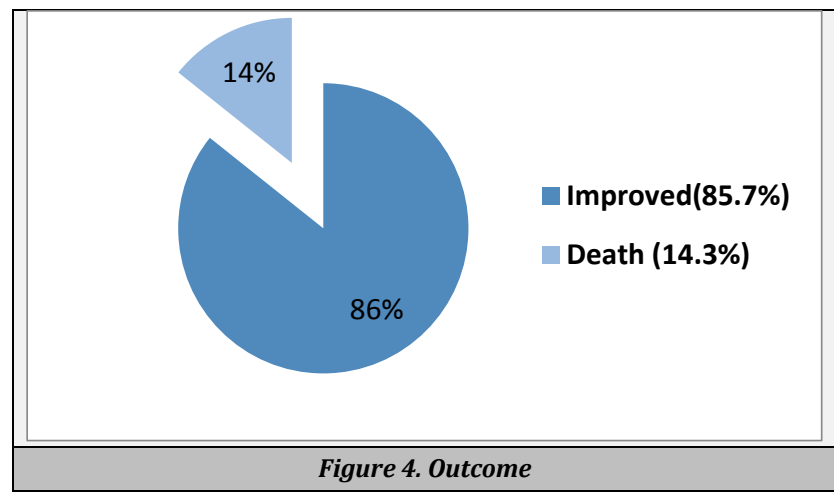

\begin{tabular}{|c|c|c|c|c|}
\hline Study & $\begin{array}{c}\text { Size of Studied } \\
\text { Population (n) }\end{array}$ & $\begin{array}{c}\text { Follow-Up } \\
\text { Period (Years) }\end{array}$ & ICH (n) & $\begin{array}{c}\text { Frequency } \\
\text { (\%) }\end{array}$ \\
\hline Stieltjes $^{10}$ et al (2005) & 4000 & 10 & 123 & 3.1 \\
\hline Nuss $^{9}$ et al (2001) & 3269 & 5 & 88 & 2.7 \\
\hline de Tezanos $^{11}$ et al (1992) & 1410 & 31 & 156 & 11.1 \\
\hline Klinge $^{8}$ et al (1999) & 744 & 20 & 30 & 4 \\
\hline Andes $^{12}$ et al (1984) & 140 & 2 & $\sim 6$ & 4.5 \\
\hline Ghosh $^{6}$ et al (2005) & 600 & 9 & 43 & 7.1 \\
\hline Bentancor $^{3}$ et al (1992) & 64 & 25 & 10 & 15.6 \\
\hline Revel-Vilk $^{13}$ et al (2004) & 172 & 16 & 18 & 10.5 \\
\hline Antunes $^{1}$ et al (2003) & 401 & 15 & 45 & 11.2 \\
\hline Traivaree ${ }^{14}$ et al (2007) & 176 & 9 & 11 & 6.3 \\
\hline Our Study & 430 & 2 & 14 & 3.26 \\
\hline \multicolumn{5}{|l}{ Table 1. Data Comparison } \\
\hline
\end{tabular}

$3.26 \%$ (14) of patients with bleeding disorders presented with ICH over 2 years. M: F ratio was $13: 1$. $78.6 \%$ had Haemophilia A, 1 (7.1\%) each had Haemophilia B, Factor XIII deficiency and Hypofibrinogenemia respectively (Figure 1). 13 (92.9\%) had severe Haemophilia A or B and 1 (7.1\%) had mild Haemophilia B. Their ages ranged from 2 - 69 years (average22.07 years). $50 \%$ were adults, with oldest being 69 years. Out of 7 children with Intracranial bleed, $5(71.4 \%)$ were $<5$ years.

$2(18.2 \%)$ with Haemophilia A had inhibitors. None were hypertensive or positive for transfusion transmitted infections-HIV, HBsAg or HCV. There was history of trauma in 9 (64.3\%). All (100\%) had severe headache, $21.4 \%$ had vomiting and $28.6 \%$ had seizures at presentation. 3 (21.4\%) were unconscious on admission, of whom 2 died. 5 (35.7\%) had dullness of consciousness. Subdural haemorrhage (SDH) was seen in $9(64.3 \%)$, subarachnoid haemorrhage in 1 (7.1\%), epidural bleed in $1(7.1 \%)$, and intraparenchymal bleed in 3 (21.4\%) Figure 2. All patients received appropriate factor replacement and supportive treatment (Figures $3 \& 4$ )

\section{DISCUSSION}

Intracranial haemorrhage (ICH) is the most serious bleeding event which may lead to disabling sequelae and death and leading cause of morbidity and mortality in patients with bleeding disorders. $3.26 \%$ of our patients with bleeding disorders presented with ICH over a period of 2 years. This compares favourably with those reported from other studies where up to $10 \%$ of the patients have this complication. ${ }^{10-13}$, All $(100 \%)$ had severe headache, $21.4 \%$ had vomiting and $28.6 \%$ had seizures at presentation. Thus headache was a universal and an early symptom to suspect intracranial bleed in patients with bleeding disorders. ICH occurs in a good number of adults contrary to popular conception, suggestive of general age-related risk factors like hypertension in aging haemophiliacs.
Subdural haemorrhage was seen in $64.3 \%$, subarachnoid haemorrhage in $7.1 \%$, epidural bleed in $7.1 \%$, and intraparenchymal bleed in $21.4 \%$. Intracranial bleeds cause rapid deterioration of CNS brain function and in severe cases, herniation of the brainstem and death. If the bleeding is stopped with rapid clotting factor concentrate (CFC) replacement, adverse clinical effects can be avoided. The degree of injury is volume and duration dependent and if needed the blood at surgically approachable sites (in particular subdural haematomas) will be evacuated by neurosurgery which requires providing adequate CFC replacement to stop the bleeding as well as for haemostatic coverage for the procedure. In addition to CFC replacement and neurosurgery, aggressive airway management is necessary for comatose or incapacitated patients and also as required in adjunctive management for injury-associated increased intracranial pressure. ${ }^{16}$ In case of intraparenchymal haemorrhage, even small haemorrhages can induce permanent structural and/or neurologic sequelae, in particular, if the anatomic site of the bleed is essential for routine brain function. ${ }^{11,14,12}$

Replacement with FVIII or FIX must occur first or in parallel with any intervention in a patient with bleeding disorders who are critically ill. Enough CFC must be infused initially to reduce or stop bleeding and then given as often as necessary to permit healing from the injury. The key principles of clotting factors dosing strategy to treat CNS haemorrhage in bleeding disorders are: 1 . Infusion of appropriate factors to maintain normal physiologic levels initially $(100 \%$ correction). 2. Frequent infusion of factors is needed to make sure that the factor level does not fall below physiologic levels (i.e., a minimum of 50\%). 3. Frequent monitoring of factor levels is desirable to ensure that a minimum of $50 \%$ of factor levels are being achieved. ${ }^{16}$

In Patients with inhibitors and a CNS bleed (or any other life- or limb-threatening haemorrhage) alternative haemostatic replacement strategies is needed. This can be higher doses of FVIII/FIX or bypassing agents like activated prothrombin complex concentrates (aPCCs) or recombinant factor VIIa (rFVIIa). The availability of aPCCs and rFVIIa has dramatically improved the clinical outcomes in inhibitor patients. Morbidity and mortality in uncontrolled CNS bleeding is high and aggressive haemostatic replacement using any or sometimes all of these options is required. ${ }^{16}$

The duration of CFC replacement therapy following CNS bleeding is not well-defined. The risk of recurrent bleeding in the initial days to weeks following a haemorrhage is high. It is prudent to maintain circulating factor levels above $50 \%$ at all times up to three weeks following a CNS bleed in order to minimize the re-bleed risk. A longer duration may be needed if an extensive neurosurgical procedure was required to treat the patient. Furthermore, even after maintaining physiologic levels in the normal range for an extensive period, consideration needs to be given to slowly weaning the CFC replacement therapy like a period of secondary prophylaxis. The duration of the secondary prophylaxis regimen depends on many factors such as the availability of CFCs, severity of injury and associated conditions, patient willingness to adhere to the regimen, rehabilitative regimens, etc. ${ }^{16}$

All our patients received appropriate CFC replacement and supportive treatment. Only around a third of our patients in this series needed surgical intervention; hence the basic 
management of intracranial bleed in patients with bleeding disorders is mainly medical with clotting factor replacement and clinical observation for signs of deterioration. All patients with history of ICH were recommended for long term factor prophylaxis. ${ }^{17,16}$

\section{CONCLUSIONS}

$3.26 \%$ of patients with bleeding disorders presented with intracranial bleed in this series. Majority of patients with ICH had severe Haemophilia A with a history of antecedent trauma. In paediatric age group, most of them were below 5 years. Headache was the commonest presentation of ICH in bleeding disorders and hence astute and keen clinical suspicion is paramount for instituting early treatment and better salvage. Subdural bleed was most common in this series. Majority responded to conservative management with factor support and thus intracranial bleeds can be managed conservatively in most bleeding disorder patients.

\section{REFERENCES}

[1] Antunes SV, Vicari P, Cavalheiro S, et al. Intracranial haemorrhage among a population of haemophilic patients in Brazil. Haemophilia 2003;9(5):573-7.

[2] Bentancor N, Lavalle E, Vila VM, et al. Intracranial haemorrhage in haemophiliacs. Study of 10 episodes. Sangre (Barc) 1992;37(1):43-6.

[3] Eyster ME, Gill FM, Blatt PM, et al. Central nervous system bleeding in haemophiliacs. Blood 1978;51(6):1179-88.

[4] Martinowitz U, Heim M, Tadmore R, et al. Intracranial haemorrhage in patients with haemophilia. Neurosurgery 1986;18(5):538-41.

[5] Ghosh K, Nair AP, Jijina F, et al. Intracranial haemorrhage in severe haemophilia: prevalence and outcome in a developing country. Haemophilia 2005;11(5):459-62.

[6] Kulkarni R, Lusher JM. Intracranial and extracranial haemorrhages in newborns with haemophilia: a review of literature. J Pediatr Haematol Oncol 1999;21(4):289-95.
[7] Klinge J, Auberger K, Auerswald G, et al. Prevalence and outcome of intracranial haemorrhage in haemophiliacs a survey of the paediatric group of the German Society of Thrombosis and Haemostasis (GTH). European Journal of Pediatrics 1999;158(Suppl 3):S162-S5.

[8] Nuss R, Soucie JM, Evatt B. Changes in the occurrence of and risk factors for haemophilia-associated intracranial haemorrhage. American Journal of Haematology 2001;68(1):37-42.

[9] Teasdale G, Maas A, Lecky F, et al. The Glasgow Coma Scale at 40 years: standing the test of time. Lancet Neurol 2014;13(8):844-54.

[10] Stieltjes N, Calvez T, Demiguel V, et al. Intracranial haemorrhages in French haemophilia patients (19912001): clinical presentation, management and prognosis factors for death. Haemophilia 2005;11(5):452-8.

[11] De Tezanos PM, Fernandez J, Bianco PPR. Update of 156 episodes of central nervous system bleeding in haemophiliacs. Haemostasis 1992;22(5):259-67.

[12] Andes WA, Wulff $K$, Smith WB. Head trauma in haemophilia. A prospective study. Archives of Internal Medicine 1984;144(10):1981-3.

[13] Revel-Vilk S, Golomb MR, Achonu C, et al. Effect of intracranial bleeds on the health and quality of life of boys with haemophilia. Journal of Pediatrics 2004;144(4):4905.

[14] Traivaree C, Blanchette V, Armstrong D, et al. Intracranial bleeding in haemophilia beyond the neonatal period - the role of CT imaging in suspected intracranial bleeding. Haemophilia 2007;13(5):552-9.

[15] Silverstein A. Intracranial bleeding in haemophilia. Archives of Neurology 1960;3:141-57.

[16] Hoots WK. Emergency care issues in haemophilia. Treatment of Haemophilia, November 2007, No. 43. Montreal, Quebec: World Federation of Haemophilia, 2007. http://www1.wfh.org/ publication/files/pdf1196.pdf. Accessed June 22, 2012.

[17] De Behnke DJ, Angelos MG. Intracranial haemorrhage and haemophilia: case report and management guidelines. J Emerg Med 1990;8(4):423-7. 